\title{
The Optimization for Frontal Impact Pulse of SUV Based on Thickness Matching
}

\author{
Wen-Tao YUAN*, Yun-Qing ZHANG, Hui-Xia LIU, Xiao WANG \\ School of Mechanical Engineering, Jiangsu University, 212013 Zhenjiang, China \\ *2226294102@qq.com
}

\begin{abstract}
Keywords: Frontal impact, Shock wave, Occupant injury, Finite element analysis, Multi-objective optimization.
\end{abstract}

\begin{abstract}
The frontal impact waveform is of great significance for occupant protection and automobile safety. According to the structure of the front engine room of the vehicle, a SUV frontal crash waveform is simplified by the simulation. The sensitivity analysis of the waveform characteristic parameters was carried out, and the influence of the large waveform characteristic parameters on the occupant injury was selected. The response surface model based on the energy absorbing area of sheet metal thickness as design variables, vehicle quality and waveform approximation coefficient as the target, parts invasion as constraints, using PSO particle swarm algorithm to optimize collision waveform, the optimization results show that the vehicle frontal impact waveform and the target waveform is closer to the wave approximation coefficient decreased by $51.1 \%$ and, vehicle quality is reduced by $0.7 \%$, in the improvement of vehicle crash worthiness optimization at the same time, the requirement of the light weight era.
\end{abstract}

\section{Introduction}

The traffic accident situation is various, which a head-on collision is most common, and the death toll topped [1]. The core purpose of Vehicle crash safety design is to protect the safety of passengers. When a head-on collision occurs, the movement of the vehicle is blocked and the occurrence of collapse. The positive impact deceleration waveform can not only characterize the vehicle frontal collision response and reflect the vehicle frontal impact performance, but also it is related to occupant injury closely. Reasonable head-on collision deceleration waveform can effectively reduce occupant injury, therefore to optimize frontal impact waveform has an important significance [2] .

In this paper, we will consider the critical parts of the intrusion and vehicle quality, combined with the experimental design, response surface and the technology of multi-objective optimization of particle subgroup to optimize the SUV collision deceleration waveform.

\section{The Simplification of the Frontal Collision and the Development of the Target Waveform}

The collision deceleration waveform can reflect the response of vehicle collision and the relationship between vehicle body structure and occupant injury. Because of the nonlinearity of vehicle collision, generally deceleration waveform is very complex. So it can not be directly used for structure optimization design[3], so as to research the relationship between collision waveform and occupant injury, the development of target waveform, we will simplify collision waveform ,extract the important characteristic parameters of the collision process, ignore the noise signal which has no value.

\section{Collision Waveform Simplification}

Through the analysis of typical vehicle crash test and a large number of literature summary by many scholars, the collision waveform has mean square wave, square wave, spire equivalent square wave, trapezoidal wave, double gradient approximation wave, double step waveform and so on[4]. The model researched in this paper is the compact SUV, vehicle finite element model as shown in Figure 1.According to a large number of scholars study[5-9], we found that a head-on collision process of this kind of structure models can be divided into two stages: (1) the stage before wall barrier and 
engine contact, longitudinal energy absorbing happened collapse deformation; (2) the stage after wall barrier and engine contact, crushing and deformation components of engine mounting point connection parts and the back of the engine occurs. Therefore, combined with the structural characteristics of the vehicle, the front collision waveform should be presented two steps, so the choice of double step waveform for the waveform simplified form, as shown in figure 2 . The corresponding times of $\mathrm{A}, \mathrm{B}, \mathrm{C}, \mathrm{D}, \mathrm{E}, \mathrm{F}$, were $\mathrm{tA}, \mathrm{tB}, \mathrm{tC}, \mathrm{tD}, \mathrm{tE}, \mathrm{tF}$, The corresponding values of $\mathrm{BC}$ steps and DE steps are respectively $\mathrm{H} 1$ and $\mathrm{H} 2$, the slope of $\mathrm{AB}$ segment, $\mathrm{CD}$ segment and $\mathrm{EF}$ segment is S1, S2 and S3.

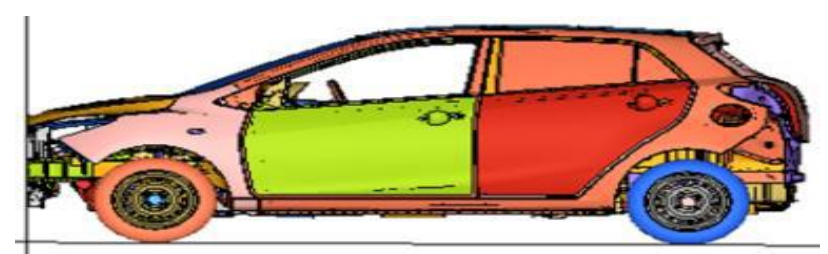

Figure 1. SUV vehicle finite element model.

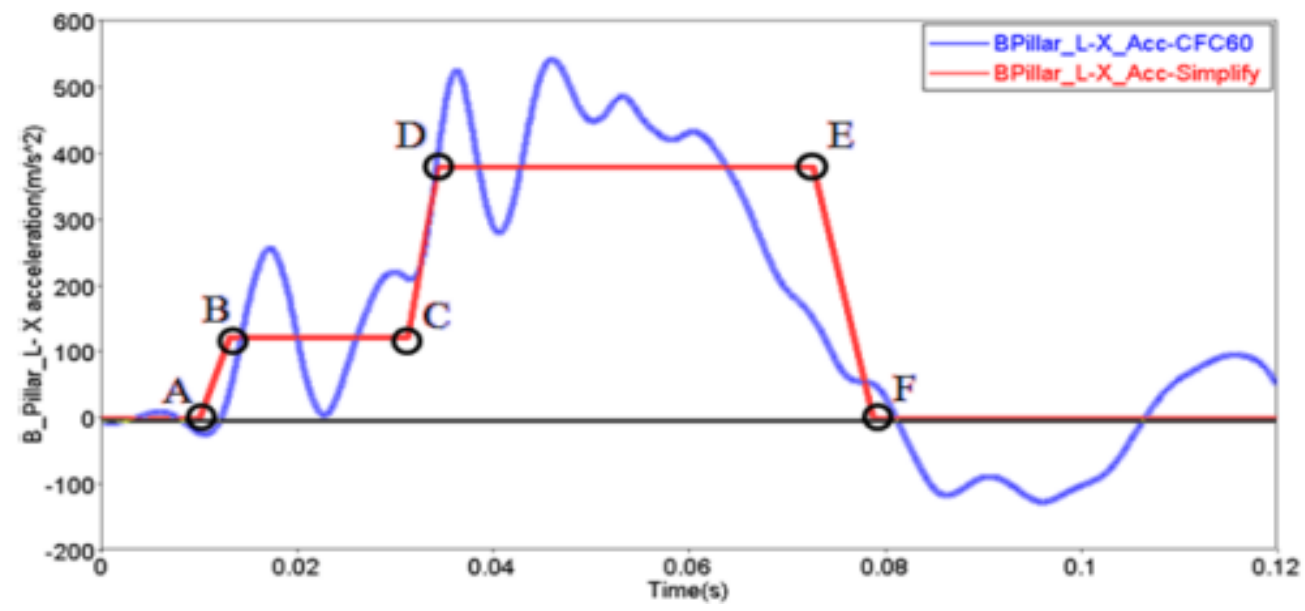

Figure 2. Simplified waveform of collision and double step simplified waveform.

According to the structure of the model, the simplified waveform of the double step is equivalent to the original waveform, and the simplified waveform must meet the following three conditions:

(1)The dynamic compression of the engine is equal before the engine is stopped.

$$
v_{0}\left(t_{C}-t_{A}\right)-\int_{t_{A}}^{t_{C}} d t \int_{t_{A}}^{t_{C}} a_{\text {simplify }} d t=d
$$

V0 is the initial velocity of the collision, a simplify is the collision reduction velocity, $d$ is the front dynamic pressure burst of the engine.

(2)The maximum dynamic pressure collapse is equal during the whole vehicle collision

$$
v_{0}\left(t_{E}-t_{A}\right)-\int_{t_{A}}^{t_{E}} d t \int_{t_{A}}^{t_{E}} a_{\text {simplif } j} d t=D
$$

$\mathrm{d}$ is the maximum dynamic pressure of vehicle.

(3)The vehicle impact speed change is equal

$$
\int_{0}^{t_{F}} a_{\text {simplify }} d t=\Delta v_{1}+\Delta v_{2}+\Delta v_{3}=\Delta v
$$

$\Delta \mathrm{v} 1$ is equivalent to the area surrounded by the horizontal coordinates and tA to tC reduced speed curve, $\Delta \mathrm{v} 2$ is equivalent to the area surrounded by the horizontal coordinates and $\mathrm{tC}$ to $\mathrm{tE}$ reduced speed curve, $\Delta \mathrm{v} 3$ is equivalent to the area surrounded by the horizontal coordinates and $\mathrm{tE}$ to $\mathrm{tF}$ reduced speed curve, $\Delta \mathrm{v}$ is equivalent to the area surrounded by the horizontal coordinates and 
reduced speed curve. Based on the above analysis and calculation, the coordinate values of the double step waveform are shown in Table 1.

Table 1. Coordinate values of the characteristic points of the double step waveform.

\begin{tabular}{|c|c|c|c|c|c|}
\hline $\begin{array}{c}\text { characteristic } \\
\text { points }\end{array}$ & $\begin{array}{c}\text { Horizontal } \\
\text { coordinate(s) }\end{array}$ & $\begin{array}{c}\text { Vertical } \\
\text { coordinate } \\
(\mathrm{m} / \mathrm{s} 2)\end{array}$ & $\begin{array}{c}\text { characteristic } \\
\text { points }\end{array}$ & $\begin{array}{c}\text { Horizontal } \\
\text { coordinate(s) }\end{array}$ & $\begin{array}{c}\text { Vertical } \\
\text { coordinate } \\
(\mathrm{m} / \mathrm{s} 2)\end{array}$ \\
\hline $\mathrm{A}$ & 0.0100497 & 0 & $\mathrm{D}$ & 0.0342750 & 380.6691 \\
\hline $\mathrm{B}$ & 0.0130579 & 123.5949 & $\mathrm{E}$ & 0.0726003 & 380.6691 \\
\hline $\mathrm{C}$ & 0.0311502 & 123.5949 & $\mathrm{~F}$ & 0.0788000 & 0 \\
\hline
\end{tabular}

\section{Sensitivity Analysis of Waveform Characteristic Parameters}

In order to provide a reasonable target for collision waveform optimization, we will analyses the sensitivity of occupant comprehensive damage value WIC, Head injury(HIC36), Cumulative chest acceleration $\left(\mathrm{T}_{3 \mathrm{~ms}}\right)$ and Chest compression by Waveform characteristic parameter $\mathrm{h} 1, \mathrm{~h} 2, \mathrm{~s} 1, \mathrm{~s} 2, \mathrm{tc}$, which find the waveform parameters of larger damage effects for occupant injury and adjust waveform, set target waveform. We can summarize something from the calculation results of the waveform characteristic parameters derived from the sensitivity of each response, the effect of $\mathrm{H} 2$ on occupant injury is largest. From 4 major injury indicators (WIC, Head injury, Chest cumulative $3 \mathrm{~ms}$ acceleration, Chest compression), we find that the effect of h1 and h2 on occupant injury is largest,h1 and the value of occupant injury are negatively correlated,h2 and the value of occupant injury are positively correlated. From Pareto chat of main injury indexes of crew, we can analyse that the value of occupant injury and s1,s2 are positively correlated, the value of occupant injury and $\mathrm{tC}$ are negatively correlated.

\section{Target Waveform Formulation}

According to the paper[10], when the vehicle collision reduced velocity is greater than $35 \mathrm{~g}$, it is difficult to make occupant gain better protection only by adjust occupant restraint system parameters and not promote body anti-impact performance, therefore, in this paper, the value of second step wave peek of double step waveform is $35 \mathrm{~g}$, the $\mathrm{H} 2$ value is $35 \mathrm{~g}$. due to no changes in the speed of the vehicle, Reducing $\mathrm{H} 2$ will cause other wave parameters change. Assuming that the vehicle collision time is constant, $\mathrm{tF}$ remains unchanged, because the occupant injury is related to $\mathrm{S} 1, \mathrm{~S} 2$ positively, the slope $\mathrm{S} 1, \mathrm{~S} 2$ is larger, the occupant injury is bigger. The S1, S2 at least should remain unchanged. At the same time, $\mathrm{tC}, \mathrm{h} 1$ and occupant injury are negatively correlated, $\mathrm{tC}, \mathrm{h} 1$ value is small, the occupant injury is small.so the value of $\mathrm{tC}$ and $\mathrm{h} 1$ should be increased with the decrease of $h 2$. Because the elastic modulus of body material is unchanged, namely the material elastic properties did not change, the rebound stiffness of the vehicle after the collision is also unchanged, so the slope of the S3 will not change. Based on the principle of conservation of the change of the velocity of collision, the equivalent double step target waveform is obtained by establishing the relationship formula. As shown in Figure 3,



Figure 3. Waveform of frontal collision 


\section{Collision Waveform Optimization Based on Material Thickness Matching}

\section{Design Variable Selection}

In order to make the collision waveform and the target waveform close, in this paper, we will use the material thickness matching optimization method, take thickness of sheet metal parts in energy absorption zone as the design variables, to improve the collision waveform by adjusting the sheet metal thickness. Design variables and range selection are shown in Figure 4 and table 2.



1-Engine hood outer panel,2-Stringer L1 Internal plate,3-Engine hood inner panel,4-Wheel package component (middle),5-Stringer L2 Internal plate,6-Front corner support plate,7-floor stringer,8-Middle passage segment,9-Floor reinforcement, 10-Middle passage front,11-Front lower cross beam ,12-stringer L2 Outer plate ,13-Front anti collision beam inner plate.

Figure 4. Scatic diagram of design variables

Table 2. Design variables and their range of variation

\begin{tabular}{|c|c|c|c|c|}
\hline Variable name & $\begin{array}{c}\text { Variable } \\
\text { code }\end{array}$ & $\begin{array}{c}\text { initial } \\
\text { value/mm }\end{array}$ & $\begin{array}{c}\text { Lower limit } \\
\text { value/mm }\end{array}$ & $\begin{array}{c}\text { Upper limit } \\
\text { value/mm }\end{array}$ \\
\hline Front anti collision beam inner plate & $\mathrm{T} 1$ & 1.10 & 0.90 & 1.30 \\
\hline Engine hood outer panel & $\mathrm{T} 2$ & 0.60 & 0.30 & 0.80 \\
\hline Engine hood inner panel & $\mathrm{T} 3$ & 0.70 & 0.40 & 0.90 \\
\hline Wheel package component (middle) & $\mathrm{T} 4$ & 1.65 & 1.25 & 1.85 \\
\hline Front lower beam & $\mathrm{T} 5$ & 1.15 & 0.90 & 1.35 \\
\hline Middle passage front & $\mathrm{T} 6$ & 0.60 & 0.40 & 0.80 \\
\hline Floor reinforcement & $\mathrm{T} 7$ & 1.75 & 1.30 & 1.95 \\
\hline Middle passage segment & $\mathrm{T} 8$ & 1.70 & 1.50 & 1.90 \\
\hline Front corner support plate & $\mathrm{T} 9$ & 1.50 & 1.30 & 1.70 \\
\hline Floor stringer & $\mathrm{T} 10$ & 1.95 & 1.75 & 2.00 \\
\hline Stringer L2 Outer plate & $\mathrm{T} 11$ & 1.85 & 1.60 & 2.00 \\
\hline Stringer L1 Internal plate & $\mathrm{T} 12$ & 1.60 & 1.30 & 1.75 \\
\hline Stringer L2 Internal plate & $\mathrm{T} 13$ & 1.75 & 1.50 & 1.95 \\
\hline
\end{tabular}

Table 3. Response surface correlation coefficient $\mathrm{R} 2$ and its correction value $R_{\text {adj }}^{2}$

\begin{tabular}{|c|c|c|c|c|c|c|c|c|}
\hline response surface & NISE & MASS & SW_X & SW_Z & Brake_X & Brake_Z & Acc_X & Acc_Z \\
\hline$R^{2}$ & 0.948 & 0.931 & 0.973 & 0.950 & 0.976 & 0.974 & 0.966 & 0.939 \\
\hline$R_{a d j}^{2}$ & 0.902 & 0.927 & 0.959 & 0.940 & 0.930 & 0.929 & 0.946 & 0.919 \\
\hline
\end{tabular}

\section{Response Surface Model}

In order to improve the optimization efficiency, the response surface model is used to replace the finite element program. The super Latin method collects 138 sets of sample points, according to the relationship complexity of the different performance of collision response and design variables , select the appropriate response surface order, established the Reduced velocity waveform approximation coefficient NISE, quality of vehicle MASS, the quality of vehicle steering column intrusion SW_X and SW_Z, the quality of brake pedal intrusion Brake_X and Brake_Z, the quality 
of accelerator pedal intrusion Acc_ $X$ and Acc_Z response surface, NISE represents the degree of approximation of the collision waveform and the target waveform, The calculation formula is as follows:

$$
N I S E(f, g)=\frac{\int_{0}^{\infty}[f(t)-g(t)]^{2} d t}{\int_{0}^{\infty} f(t)^{2} d t+\int_{0}^{\infty} g(t)^{2} d t}
$$

$f(t)$ is reduced velocity sample wave function, $g(t)$ is reduced velocity target waveform function. After the response surface is established, the waveform approximation function and the vehicle mass expression are as follows:



The correlation coefficient $\mathrm{R}^{2}$ and the modified correlation coefficient $\mathrm{R}^{2}$ adj can be used to test the accuracy of the response surface, and its value is close to 1 , which indicates that the accuracy of the response surface is higher. The accuracy of the constructed response surface is shown in table 3, all the correlation coefficients are above 0.9 , indicating that the response surface is more reliable.

\section{Collision Waveform Curve Optimization}

Multi-objective particle swarm optimization algorithm MOPS are based on improved PSO and take the selected sheet metal thickness as design variables, take the minimum waveform approximation coefficient NISE and the minimum vehicle quality as target, take the intrusion of steering column, brake pedal, accelerator pedal in the direction of $\mathrm{X}$ and $\mathrm{Z}$ as constraint, then carry out multi-objective optimization. Specific optimization models are as follows:



Note: The limit value of each constraint in the bracket is the enterprise target requirement. NISE-Reduced velocity waveform curve approximation coefficient, MASS — Vehicle quality, SW_ $\mathbf{X}^{\mathrm{U}}$ - the upper limit value of steering column intrusion in $\mathbf{X}$ direction. $\mathbf{S W} \_\mathbf{Z}^{\mathrm{U}}$ - the upper limit value of steering column intrusion in $\mathbf{Z}$ direction. Brake_ $\mathbf{X}^{\mathrm{U}}$ - the upper limit value of brake pedal intrusion in $\mathrm{X}$ direction. Brake_ $\mathbf{Z}^{\mathrm{U}}$ - the upper limit value of brake pedal intrusion in $\mathrm{Z}$ direction. Acc $\mathbf{X}^{\mathrm{U}}$ - the upper limit value of accelerator pedal intrusion in $\mathrm{X}$ direction. Acc_ $\mathbf{Z}^{\mathrm{U}}$ - the upper limit value of accelerator pedal intrusion in $\mathrm{Z}$ direction. $\mathbf{T i}^{\mathrm{L}}$ - the lower limit value of optimal design variables. $\mathbf{T i}^{\mathrm{U}}$ - the upper limit value of optimal design variables.

Because the waveform approximation coefficient and the vehicle quality cannot reach the 
minimum at the same time, multi-objective optimization does not exist the unique solution, but a Pareto non-inferior set, which requires the decision makers to choose the optimal solution from the solution sets. After 10000 iterations of the algorithm, vehicle quality MASS and Pareto front of the reduced velocity waveform approximation coefficient NISE are shown gradually, as shown in Figure 5.Based on the principle of making reduced velocity waveform approximation coefficient minimum by no increasing vehicle quality, the final thickness of sheet metal optimization value are shown in table 4.



Note: the Yellow curve is a curve fitting iteration between data points, the black dots represent non-Pareto front solution and Iteration does not violate the constraint conditions, the blue points are Pareto front solution, the Green Points are recommended optimization solution for the MOPS algorithm.

Figure 5. NISE and Pareto MASS frontier

Table 4. Comparison of sheet metal thickness before and after optimization

\begin{tabular}{|c|c|c|c|}
\hline Variable name & Variable code & initial value $/ \mathrm{mm}$ & Optimal value $/ \mathrm{mm}$ \\
\hline Front anti-collision beam inner plate & T1 & 1.10 & 0.90 \\
\hline Engine hood outer panel & T2 & 0.60 & 0.50 \\
\hline Engine hood inner panel & T3 & 0.70 & 0.40 \\
\hline Wheel package component (middle) & T4 & 1.65 & 1.85 \\
\hline Front lower cross beam & T5 & 1.15 & 0.90 \\
\hline Middle passage front & T6 & 0.60 & 0.40 \\
\hline Floor reinforcement & T7 & 1.75 & 1.30 \\
\hline Middle passage segment & T8 & 1.70 & 1.65 \\
\hline Front corner support plate & T9 & 1.50 & 1.30 \\
\hline Floor Stringer & T10 & 1.95 & 2.00 \\
\hline StringerL2 Outer plate & T11 & 1.85 & 2.00 \\
\hline Stringer L1 Internal plate & T12 & 1.60 & 1.30 \\
\hline Stringer L2 Internal plate & T13 & 1.75 & 1.95 \\
\hline
\end{tabular}

Table 5. Comparison of safety performance data before and after optimization

\begin{tabular}{|c|c|c|c|c|c|c|}
\hline Measurement project & & target & $\begin{array}{c}\text { Original } \\
\text { scheme }\end{array}$ & $\begin{array}{c}\text { thickness } \\
\text { matching }\end{array}$ & $\begin{array}{c}\text { Improvement } \\
(\%)\end{array}$ & $\begin{array}{c}\text { Beyond } \\
\text { target }(\%)\end{array}$ \\
\hline NISE & - & minimum & 0.05414 & 0.02650 & 51.1 & - \\
\hline \multirow{2}{*}{ Vehicle quality(t) } & - & minimum & 1.3300 & 1.3202 & 0.7 & - \\
\hline \multirow{2}{*}{ steering column(mm) } & $\mathrm{X}$ & $\leq 50$ & 23.5 & 23.1 & 1.7 & 53.8 \\
\cline { 2 - 7 } & $\mathrm{Z}$ & $\leq 60$ & 19.5 & 28.3 & -45.1 & 52.8 \\
\hline \multirow{2}{*}{ brake pedal(mm) } & $\mathrm{X}$ & $\leq 75$ & 49.4 & 71.5 & -44.7 & 4.70 \\
\cline { 2 - 7 } & $\mathrm{Z}$ & $\leq 72$ & 19.7 & 39.9 & -102.5 & 44.6 \\
\hline \multirow{2}{*}{ accelerator pedal $(\mathrm{mm})$} & $\mathrm{X}$ & $\leq 75$ & 15.4 & 10.0 & 35.1 & 86.7 \\
\cline { 2 - 7 } & $\mathrm{Z}$ & $\leq 72$ & 74.4 & 71.9 & 3.4 & 0.10 \\
\hline
\end{tabular}


Putting thickness value of each sheet metal into finite element simulation model to recalculate. Waveform comparison diagram and each collision safety performance data obtained are shown in Figure 6 and table 5.

Comparative analysis of original scheme in figure 3.3 and the thickness matching optimization collision waveform, the approximation degree of collision waveform in original scheme and the target waveform is low. Through the sheet material thickness optimization, the value of waveform approximation coefficient NISE is $68.1 \%$ lower than the original scheme, the collision waveform is more closer to the target waveform, the positive collision safety performance is improved at the same time. The quality of vehicle quality MASS compared with the original scheme reduces $6.7 \mathrm{~kg}$, a decline of $0.5 \%$, to a certain extent and meet the requirements of lightweight. Through analysis of the key components of intrusion data, some parts of intrusive value was increased but lower than that of the objectives of the enterprise. In addition, the accelerator pedal intrusion in $\mathrm{Z}$ direction is in the edge of target, the rest over the limit has a certain margin, the material thickness optimization makes intrusion have reduced.

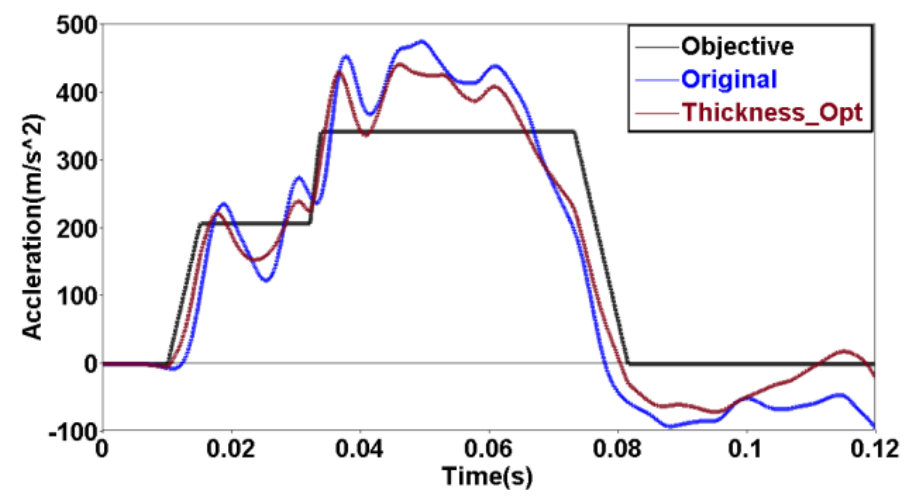

Figure 6. Comparison of the impact waveform before and after optimization

\section{Concluding Remarks}

This paper takes a SUV model as the research object, according to energy absorption zone structure, simplify frontal impact waveform by the application of double step waveform, carry out the sensitivity analysis of occupant injury through waveform characteristic parameter, we find that the parameters of $\mathrm{H} 1$ and $\mathrm{H} 2$ has the greatest effect on occupant injury, and $\mathrm{H} 1, \mathrm{H} 2$ respectively positive and negative correlated with the value of occupant injury. According to the results of sensitivity analysis and the occupant tolerance limit, the target of the impact waveform is established. Response surface model is built and on this basis we carry out multi-objective optimization of collision waveform, optimized waveform approximation coefficient NISE decreased from 0.05414 to 0.02650 , a decline of $51.1 \%$, and the collision waveform is closer to the target waveform, the vehicle quality reduced from $1.3300 \mathrm{t}$ to $1.3202 \mathrm{t}$, a decline of $0.7 \%$. The optimization of material thickness matching not only improves the safety performance of automobile collision, but also realizes the requirement of lightweight.

\section{Reference}

1. Junyi Chen, Hongyan Wang, Ting Pan, From road traffic accident research to see our country automobile frontal impact regulation test form J. Auto.Eng 32,7(2010)

2. Libo Cao, Tengjiao Long, Huiqin Xiao, Study on the relationship between the waveform characteristics of the equivalent double step and the value of comprehensive damage of passengers J. Auto.Eng 2,3(2012).

3. Cheng Z, Pellettiere J A, Optimal Crash Pulse for Minimization of Peak Occupant Deceleration in Frontal Impact J. 1(2005). 
4. Chong Li, Haitao Zhu, Research on body acceleration and occupant chest injury in frontal crash (Proceedings of the Seventh International Symposium on automobile traffic safety,2009).

5. Matsumoto H, Sakakida M, Kurimoto K, A parametric evaluation of vehicle crash performance J.Paper;Automotive_Sector.(1990).

6. Wu J, Nusholtz G S, Bilkhu S,Optimization of vehicle crash pulses in relative displacement domain J. International Journal of Crashworthiness 4,7(2002).

7. Mark S, Effect of frontal crash pulse variations on occupant injuries (Proceedings: International Technical Conference on the Enhanced Safety of Vehicles. National Highway Traffic Safety Administration, 2003).

8. Shuai Yang, Yajun Zhang, Yanjun Hou, Shugang Xie, Study on the wave adjustment and optimization strategy of collision acceleration of front structure for the 2012 edition $C-N C A P$ (Proceedings of the annual conference of China Automotive Engineering Society,2013).

9. Xiaojun Bao, Houjun Zhang, Research on the optimization strategy of the frontal impact acceleration of a vehicle ( Proceedings of the annual conference of China Automotive Engineering Society,2014).

10. Guang Chen, Junyuan Zhang, Ledan Liu, Anti-impact design of vehicle body front structure based on substructure performance J. Auto.Eng 35, 9(2013). 